\title{
Univariate Normal Distribution
}

National Cancer Institute

\section{Source}

National Cancer Institute. Univariate Normal Distribution. NCI Thesaurus. Code C53216.

A normal distribution which models only a single variable of interest. Like the normal distribution, its shape and position are determined by the mean of the set of observations (location parameter) and its standard deviation (scale parameter). 